\title{
O ENSAIO SOBRE A CEGUEIRA E A INTERDIÇÃO AO SABOR: LITERATURA, CINEMA E PRÁTICAS DISCURSIVAS DE SUJEIÇÃO
}

\section{BLINDNESS AND THE FLAVOR INTERRUPTION: LITERATURE, CINEMA AND DISCURSIVE PRACTICES OF SUBJECTION}

\author{
SILVEIRA, Éderson Luís da ${ }^{1}$ \\ FAQUERI, Rodrigo de Freitas ${ }^{2}$
}

RESUMO: O presente artigo apresentará pronunciamentos enunciativos de compreensão de excertos extraídos do romance Ensaio sobre a cegueira, de José Saramago e do filme homônimo, dirigido pelo brasileiro Fernando Meirelles. Trata-se, portanto, de uma pesquisa qualitativa de viés exploratório e de cunho bibliográfico cujas análises serão empreendidas a partir das contribuições de Michel Foucault, Jean-Louis Flandrin e Massimo Montanari, LéviStrauss, Linda Hutcheon, Roland Barthes e Henrique Carneiro. Consideramos que a comida é também fonte de expressão e não apenas uma necessidade. Tanto quanto a necessidade de alimentar-nos nos expressamos através de hábitos alimentares, ritos e forma, (diversas) de reagir à ausência de alimentos. Nas obras ficcionais, a interdição dos alimentos é discursiva e remete ao terreno das práticas em que alguns são proibidos e outros são os que decidem, negligenciando-se princípios éticos para coisificar mulheres como moeda de troca aproximando as relações humanas de um viés utilitarista. Aos interditados, resta a negação ao direito de escolha e o afastamento de dimensões emancipatórias no que diz respeito a escolhas relacionadas ao ato de alimentar-se. Concluímos, neste contexto, que as relações de poder atravessam práticas individuais e coletivas interagindo com dimensões subjetivas dos indivíduos que resultam em formas de sujeição.

PALAVRAS-CHAVE: Alimentação, José Saramago, cinema, literatura.

\footnotetext{
${ }^{1}$ Mestre em Linguística pela UFSC, Doutorando em Linguística pela Universidade Federal de Santa CatarinaUFSC. E-mail: ediliteratus@gmail.com

${ }^{2}$ Doutorando em Letras pela Universidade Presbiteriana Mackenzie. E-mail: rodrigofaqueri@hotmail.com
} 
ASBTRACT: This article will present pronouncements of understanding of excerpts taken from the novel blindness, José Saramago and the movie of the same name, directed by Brazilian Fernando Meirelles. It is, therefore, a qualitative research of exploratory and bias of bibliographical nature whose analyses will be undertaken from the contributions of Michel Foucault, Lévi-Strauss, Jean-Louis Flandrin and Massimo Montanari and Henrique Carneiro. We believe that the food is also a source of expression and not just a necessity. As much as the need to feed us in the express through eating habits, rites and ways (several) to react to the absence of food. In fictional works, the ban of discursive and foods is the land where some practices are prohibited and others are the ones who decide, neglecting yourself ethical principles for objectifying women as a bargaining chip closer human relations a utilitarian perspective. The outlawed, remains the denial of the right of choice and the removal of emancipatory dimensions regarding the choices related to the act of feeding. Concludes therefore that configures the dynamics of power relations cross individual and collective practices interacting with subjective dimensions of individuals that result in forms of subjection.

KEYWORDS: Food, José Saramago, cinema, literature.

\section{INTRODUZINDO O PERCURSO}

A origem da palavra "alimento" está associada ao latim alere, que quer dizer "nutrir, fazer crescer, alimentar". Historicamente, a pesquisa acerca da história da alimentação no âmbito das Ciências Humanas está relacionada a uma série de pesquisadores cuja temática, em seus trabalhos, teve início desde a década de 1930. Foi quando Marc Bloch e Lucien Febvre começaram a pensar a história a partir do cotidiano, Bloch escreveu um ensaio acerca da história da alimentação e a inseriu na Encyclopédie Française de Febvre. Tal acontecimento tornou a publicação, em 1930 um marco referente ao uso da alimentação como objeto de estudo nas Ciências Humanas, mais especificamente, nos Annales, tendo ambos os autores como representantes da Primeira Geração. Na Segunda Geração dos Annales, os historiadores Fernand Braudel e Ernest Labrousse se destacaram em relação ao tema. Na obra Civilização material, economia e capitalismo, por exemplo, Braudel considerou alimentos como o milho, 


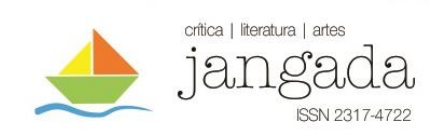

o arroz e o trigo produtos representantes da vida cotidiana, considerando o período do século XV ao século XVIII.

Posteriormente, na década de 1970 aumentou-se o interesse pela temática da alimentação e, em 1974, Jacques Le Goff e Pierre Nora passaram a considerar a história a partir do conceito de micro-história, contrapondo-se ao que consideravam predominância de uma história absoluta do passado reivindicando a coexistência de vários tipos de história (SANTOS, 2005). A coletânea Faire de l'histoire, lançada em 1974, foi traduzida no Brasil como História: novos problemas (volume 1), novas abordagens (volume 2), novos objetos (volume 3). A partir daí destacaram-se, neste âmbito, obras como História da Alimentação, organizada por JeanLouis Flandrin e Massimo Montanari, A gastronomia Francesa, de Jean-Robert Pitte e a Invenção do Restaurante, de Rebecca Spang.

No Brasil, a tradução das obras mencionadas se deu a partir da década de 1990. Não pretendendo estender-nos à exaustão na referência à obras sobre o tema, o ato de mencionar as obras assinaladas até o presente momento teve por objetivo apresentar informações sobre obras seminais que tiveram relação com os estudos sobre a Alimentação no campo das Ciências Humanas através de uma breve e não exaustiva revisão de literatura. Para quem busca se aprofundar no tema, portanto, além das obras mencionadas - principalmente História da Alimentação - indicamos a obra Comida e sociedade: uma história da alimentação, em que o professor Henrique Carneiro apresenta um panorama da produção acadêmica em torno da história da alimentação considerando uma multiplicidade de abordagens e significados sociais, culturais, éticos, étnicos, estéticos, religiosos, etc. Isso para mostrar que a alimentação é mais que uma necessidade biológica, ela permite observar a presença de ritos e costumes através de relações atravessadas pelo poder (FOUCAULT, 1979).

Segundo Carneiro (2003) a distinção social promovida pelos hábitos e rituais alimentares de diversos povos permite a observância da construção social de papéis de gênero, de identidades étnicas, regionais e também prescrições e interdições constitutivas. Regulamentações alimentares e distinções sociais estão no bojo das análises promovidas no presente artigo que aqui apresentamos, assim como estão relacionadas a instâncias específicas e particulares, articuladas ao enredo ficcional em questão.

Se considerarmos o tema em relação à Literatura podemos destacar a articulação paronímica que Roland Barthes faz entre saber e sabor no livro O prazer do texto. Considerando o original etimológico de savoir e saveur podemos destacar que tal paronímia é válida para a maioria das línguas românicas e inscreve um efeito de atratividade mútua entre os termos 


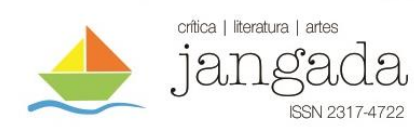

relacionando-os com o gosto da literatura. Cabe então assinalar, neste contexto, as considerações da pesquisadora Maria Alzira Seixo, da Universidade de Lisboa a este respeito:

Esse livro teve forte repercussão nos anos setenta, e a paronímia que releva nessas formas lexicais promove, segundo a tese do autor, uma alternativa de atracção mútua entre os dois conceitos, relacionados ambos com o gosto da Literatura. Esta mesma noção de gosto implica à partida uma oscilação, ou possível juntura, da dimensão estética de fenómenos culturais de carácter abstracto, apreendidos afectivamente, com uma outra dimensão, bem concreta e material, que é a de tipo gustativo. Assim, uma filosofia do gosto pode não se caracterizar apenas pelo raciocínio, em que predomina a argumentação justa que lhe confere o bom tom da adequação à matéria, mas se torna também atractiva no sentido da sua compreensão como que visual ("ver" é “compreender”), e por sugestões sensoriais múltiplas que se diriam recolhidas pelo paladar alargado, que agiria como se totalizasse a maioria das sensações de cada indivíduo em relação ao mundo e, por conseguinte, a cabal experiência de conhecimento de todos nós (SEIXO, 2014, p. 16).

Em Seixo (2014) serão consideradas as relações entre alimentação, gastronomia e literatura. No presente artigo, cabe-nos um recorte, em que a autora menciona que "o acto de comer gira primariamente em torno do instinto da fome e respectiva satisfação, que, na vida em sociedade, se completa com modos geoculturais próprios e distinções de civilização e estilos pessoais ou colectivos de vida" (SEIXO, 2014, p. 16). O que nos interessa, portanto, é de que forma a questão do sabor - da ausência de sabor, da interdição do sabor, da busca em satisfazerse para suprir a fome - se articula a uma necessidade de alimentação que instaura hábitos, comportamentos e modos de agir atravessados por relações de poder na obra de José Saramago e de Fernando Meirelles.

Considerando tal empreendimento, a teoria da adaptação da crítica canadense Linda Hutcheon (2011) será utilizada para lançar luzes à adaptação cinematográfica da obra de Saramago. A relação entre saber e sabor estabelecida por Barthes em relação ao gosto pela Literatura também será retomada em alguns momentos e as contribuições de obras sobre a história da alimentação (CARNEIRO, 2003; FLANDRIN \& MONTANARI, 1998, por exemplo) se farão presentes na análise empreendida a seguir. 


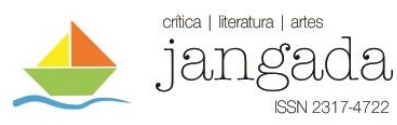

Dessa maneira, a partir dos levantamentos teóricos acima descritos, propomos observar alguns trechos extraídos do romance Ensaio sobre a cegueira, publicado em 1995, do português José Saramago em diálogo com algumas cenas da produção cinematográfica baseada em sua obra e dirigida pelo brasileiro Fernando Meirelles em 2008, sob viés da gastronomia e suas transformações que, durante séculos, estão articuladas ao princípio da sobrevivência e à adaptação culinária à arte de cozinhar.

\section{NOS INTERSTÍCIOS DA ANÁLISE}

Em Ensaio sobre a cegueira, romance e filme, a população de um país começa a sofrer com uma inédita epidemia de cegueira, classificada como "cegueira branca", pois as pessoas afirmavam começar a ver repentinamente superfícies leitosas que impossibilitavam sua visão normal. Sem saber como controlar adequadamente a situação e não aumentar o pânico entre aqueles que ainda não apresentavam os sintomas da doença, o governo começa a enclausurar os primeiros cegos em edifícios projetados para outras atividades, como manicômios. Com o alastramento da epidemia, a situação se torna caótica, e a luta pela sobrevivência em um ambiente totalmente hostil começa a aparecer dentro da narrativa.

Posto isso, propomos a análise de quatro momentos na narrativa em que acreditamos encontrar os elementos acima descritos de modo mais explícito. O primeiro e o último são dois momentos em que as personagens estão em um jantar proposto pela anfitriã da casa, a mulher do médico. Em situações diferentes, antes e depois da epidemia, a gastronomia aparece dentro da narrativa sob outra perspectiva em que podemos perceber a relação desta com a literatura e o cinema e sua função dentro da narrativa. O segundo momento refere-se à luta pela sobrevivência dentro do manicômio em que a escassez de alimentos e a imposição de leis totalitárias por aqueles que detêm o poder entre as alas do lugar obriga as personagens femininas ao extremo, sujeitando-se a uma posição humilhante, obrigadas a fazerem sexo com os homens de outra ala em troca de comida. A terceira cena analisada será a que a mulher do médico encontra comida em um depósito subterrâneo de um supermercado. Os cheiros exalados pelas comidas encontradas despertam o olfato de centenas de cegos que, privados de sua visão, aguçaram outros sentidos e também buscavam alimentos para poder sobreviver naquele momento caótico. O sabor, neste contexto, está relacionado a uma memória gustativa acionada pelo olfato dos cegos e articula-se com as obras ficcionais através de sugestões sensoriais dos 
personagens ativadas não apenas pelo raciocínio, mas pela necessidade de saciar sua fome. $\mathrm{O}$ sabor e o alimento estão então articulados a uma ausência constitutiva que permite o enfoque central da questão do alimentar-se como fundante na narrativa.

A primeira cena analisada apresenta maior destaque no quesito gastronômico na produção cinematográfica que no romance a partir da adaptação realizada. O trecho em que o médico e sua mulher estão jantando na narrativa escrita apenas aparece de maneira superficial, pois o narrador realça o interesse do médico em tentar descobrir a causa da cegueira estranha que havia sido diagnosticada em um paciente novo hoje em seu consultório:

À noite, depois do jantar, disse à mulher, Apareceu-me no consultório um estranho caso, poderia tratar-se de uma variante da cegueira psíquica ou da amaurose, mas não consta tal coisa se tivesse verificado alguma vez. Que doenças são essas, a amaurose e a outra, perguntou a mulher. $\mathrm{O}$ médico deu uma explicação acessível a um entendimento normal, que satisfez a curiosidade dela, depois foi buscar à estante os livros de especialidade, uns antigos, do tempo da faculdade, outros recentes, alguns de publicação recentíssima, que ainda mal tivera tempo de estudar. [...] (SARAMAGO, 2008, p. 29)

Neste trecho, à exceção da menção feita na primeira linha sobre o jantar tido pelo casal, não se menciona nada sobre gastronomia. Entretanto, a produção cinematográfica utiliza exatamente este elemento para criar uma atmosfera nova e elaborar um ambiente diferente nesta cena.

Como podemos observar acima, a intelectualidade do médico é destacada enquanto a ignorância e o desconhecimento de sua mulher diante de um assunto tão específico são refletidos em uma "explicação acessível" ao entendimento da personagem. Com isso, na narrativa de Saramago, tal desconhecimento da personagem a coloca em uma posição inferior à de seu esposo sem uma contrapartida.

Na produção de Meirelles, a gastronomia entra como contraponto à ignorância da mulher sobre o assunto relacionado à enfermidade discutida pelo médico, pois enquanto este aborda o assunto, a mulher está terminando de colocar à mesa um Tiramisù feito por ela, acompanhado de um vinho: 


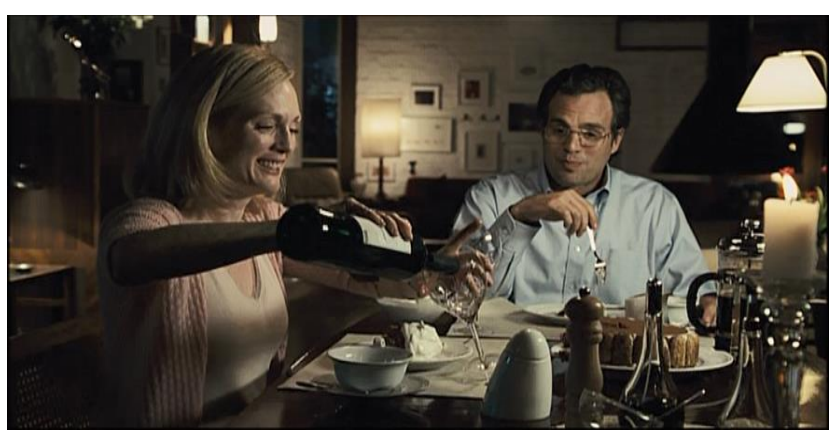

Figura 1: Cena do jantar entre a esposa e o médico

Fonte: Meirelles, 2008 [00:12:51]

A narrativa fílmica se faz valer de uma das premissas da gastronomia que associa o prazer de comer e o prazer da mesa, em que, neste último, as sensações no ato de comer vão além e perpassam os alimentos, juntando circunstâncias, como a companhia, o local, a situação e o entorno em que se come. Além disso, o roteiro se baseia no princípio de que quase nunca se come sem um algum acompanhamento e, a partir desta premissa, acrescenta o vinho como elemento na cena. Se considerarmos os estudos de Carneiro (2003) e de Jean-Louis Flandrin e Massimo Montanari (1998) podemos mencionar que tais considerações partem da expressão de hábitos, costumes e rituais que revelam significados sociais, estéticos e culturais (re) produzidos na cena. A distribuição de papéis de gênero também pode ser notada visto que à mulher cabe, na cena, a tarefa de servir o jantar enquanto que o ao homem cabe o "lugar" de ser servido e servir-se do que é servido pela mulher. Os tipos de alimentos que são apresentados também dizem respeito ao lugar social que ambos ocupam: não se trata de comida simples, mas requintada que remete a posições estratégicas na pirâmide sociocultural da humanidade. A aparência da louça e os objetos sob a mesa também revelam traços que reforçam tal posição.

Com tais acréscimos à cena, validando tal ação com a teoria de Hutcheon (2011) que destaca a adaptação de uma obra a partir da transposição anunciada e explícita, a discussão sobre a temática ganha um novo ingrediente, que é justamente o conhecimento culinário da mulher do médico e da ignorância gastronômica deste. Se a personagem feminina desconhece o significado e as origens das palavras que dão nome às doenças descritas pelo marido, o oftalmologista desconhece a diferença entre uma torta qualquer e o Tiramisù, um doce italiano do final do século XVI preparado com ovos, açúcar, queijo mascarpone ${ }^{3}$ e embebido de café, que proporciona o toque autêntico deste doce centenário.

\footnotetext{
3 “O mascarpone é um tipo de queijo cremoso, de origem italiana. Ele é feito a partir da coagulação do creme de leite quando algum tipo de ácido é acrescentado (como limão ou vinagre). Na geladeira, ele pode ser conservado por até uma semana" (HENRIQUES, 2018, s. p., grifo da autora).
} 
Temos, então, não apenas a distinção de papéis de gênero, mas a especificação que assinala uma relação entre saber e sabor, em que as artes do sabor se articulam a um saber-fazer que a mulher domina. Mais do que acentuar a predominância deste ou daquele gênero em tal instância, o que se torna produtivo é um efeito de silenciamento na obra ficcional produzido pela breve alusão a um jantar enquanto que, na produção cinematográfica, ocorre um deslocamento. A hierarquia entre homem e mulher da ficção romanesca dá lugar a uma distribuição de papéis pré-estabelecida sim, mas que permite perceber outras nuances de tal relação. Dessa forma, o sabor e o saber se aproximam em ambas as formas de manifestação artística, mas são operados através de um deslocamento que revela particularidades que remetem a lugares social e culturalmente instituídos.

Neste âmbito, o ato de estar à mesa e os saberes que são reforçados no presente cenário, sejam na conversa em que o médico retém conhecimentos acerca de doenças ou através da atividade daquela que conhece os artifícios da gastronomia, dizem muito sobre as formas culturalmente estabelecidas de atribuição e reprodução de papéis de gênero na sociedade. Porém, a diferença entre o romance e o cinema, neste caso, perpassa silenciamentos, deslocamentos e modos de perceber tal atribuição de papéis que reforça ou (quase) ultrapassa as instâncias do truísmo e da repetição de um lugar comum.

Depois da epidemia alastrada entre a população, ainda amparados pela teoria da adaptação de Hutcheon (2011), podemos afirmar que a produção fílmica remonta o jantar dos sete peregrinos na casa do médico e de sua mulher após a saída do grupo do manicômio. Enquanto que na narrativa de Saramago o destaque se dá pela falta de comida restante para o grupo no âmbito daquela refeição e para o achado da mulher do médico de um garrafão de cinco litros de água, na adaptação de Meirelles parece haver um banquete a ser servido mesmo em um momento tão delicado da narrativa:

A mulher do médico já tinha posto na mesa alguma da pouca comida que restava, depois ajudou-os a sentarem-se, disse, Mastiguem devagar, ajuda a enganar o estômago. $\mathrm{O}$ cão das lágrimas não veio pedir comida, estava habituado a jejuar, além disso deve ter pensado que não tinha o direito, depois do banquete da manhã, tirar um pouco que fosse à boca da mulher que tinha chorado, os outros parecem não ter para ele muita importância. [...] voltou com o garrafão, a luz entrava por ele, fazia cintilar a jóia que tinha dentro. Colocou-o sobre a mesa, foi buscar os copos, os melhores que tinham, de 


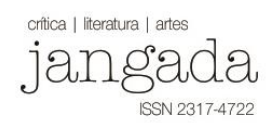

cristal finíssimo, depois, lentamente, como se estivesse a oficiar um rito, encheu-os. No fim, disse, Bebamos. [...] (SARAMAGO, 2008, pp. 262-264)

Vale ressaltar que na narrativa do escritor português esse destaque não é dado aos alimentos como é feito na produção do diretor brasileiro. Destaca-se muito mais a necessidade de se poupar os poucos alimentos que o grupo possui naquele momento e dá-se maior importância à descoberta do galão de cinco litros encontrado pela mulher do médico, algo que poderá manter o grupo hidratado por mais tempo. No excerto apresentado anteriormente, a valorização está centralizada preferencialmente na bebida que as personagens têm acesso naquele momento, reforçando a ideia inicial da existência de alimentos cuja função essencial é a de garantir a sobrevivência do ser humano.

Mais que um elemento estético, nesta cena a comida e a bebida oferecida têm como papel fundamental: a necessidade de alimentar o grupo de cegos para que estes sobrevivam. Devido a isso, a água é elevada ao patamar de uma bebida sofisticada e requintada, rara naquela situação extrema de escassez ("foi buscar os copos, os melhores que tinham, de cristal finíssimo”). A gastronomia, neste sentido, volta ao seu princípio básico que é o de alimentar e a bebida ganha contornos estéticos, ainda que tímidos, devido à menção ao receptáculo no qual vai ser compartilhada, pois apresenta, neste momento, em um dos alimentos mais essenciais e primitivos a capacidade de satisfazer a necessidade daquele grupo. No filme de Meirelles, o destaque à água também é dado, como podemos observar na imagem abaixo:

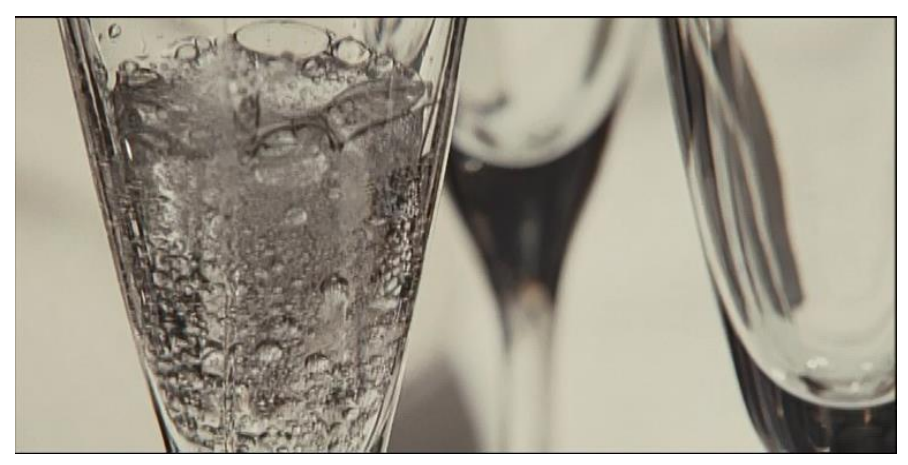

Figura 2: Cena da água

Fonte: Meirelles, 2008 [01:48:21]

Nesta imagem, a relação feita entre a água e um champanhe é visível, pois a câmera foca nas bolhas produzidas pelo gás contido na água e liberado ao ser colocado na taça. Além disso, a utilização de taças para beber tal líquido também remete à sofisticação pretendida na cena. Neste momento, a transposição explícita entre as narrativas se torna clarividente e reforça a adaptação anunciada na produção cinematográfica. 


\section{jangada}

Seguindo mais alguns segundos na mesma cena, em que a mesa pode ser vista a partir de uma tomada de cima, tem-se a ideia de um banquete servido pela mulher do médico ao grupo ali presente. Com a disposição dos alimentos alinhados aos pratos e a distribuição uniforme das porções nas travessas, assim como as taças bridando sobre a comida sob a luz central do candeeiro, tem-se a ideia de impressão estética que a gastronomia pretende trazer. O ambiente é harmonioso e remete alegria mesmo diante de uma situação caótica como a que estão passando as personagens. Antes disso, a mulher do médico apresenta aos seus "convidados" o cardápio da noite: em um canto da mesa, havia ervilhas e cenouras; no centro da mesa, azeitonas e biscoitos salgados e, na outra ponta da mesa, anchovas. ${ }^{4}$

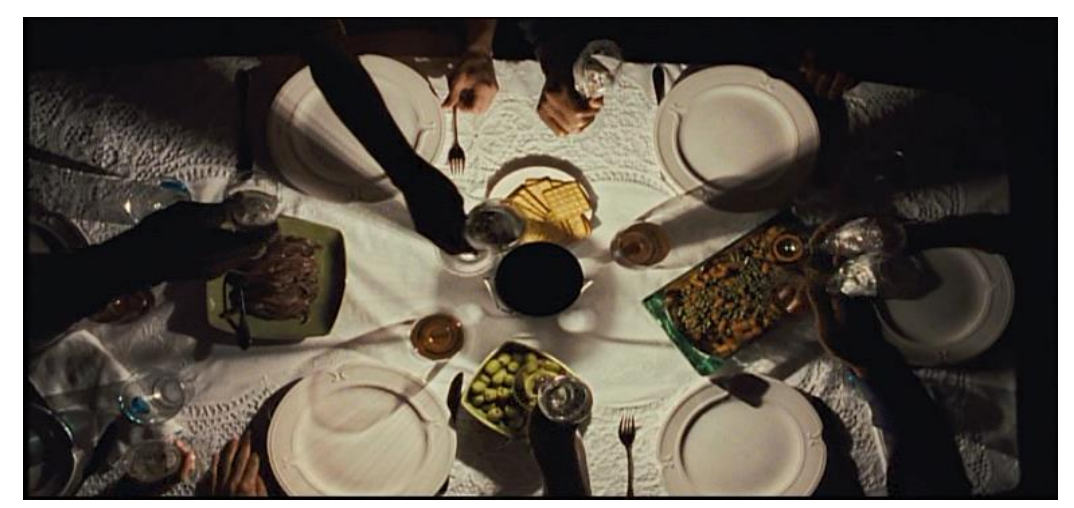

Figura 3: Cena da mesa vista de cima Fonte: Meirelles, 2008 [01:48:31]

A esta altura, cabe uma ressalva: para Carneiro (2003), o enfoque conferido ao tema da história da alimentação no escopo das investigações das Ciências Naturais frequentemente negligencia a importância das dimensões histórico-culturais no que diz respeito ao tema. Isso porque médicos e cientistas naturais consideram as Ciências Humanas como formas auxiliares no estudo da alimentação, porque estão centrados na dimensão física do tema. Tal enfoque deixa de lado, por exemplo, o fato de que a comida é também fonte de expressão e não apenas uma necessidade. Tanto quanto a necessidade de alimentar-nos nos expressamos por meio dos hábitos alimentares, de ritos e de formas (diversas) de reagir à ausência de alimentos.

Para Flandrin e Montanari (1998) a dimensão social da alimentação está relacionada a uma instância impregnada por códigos e valores que por sua vez se articulam à existência de rituais e símbolos compartilhados através da cultura. No caso das cenas em questão, a gourmetização de um copo de água ou de algumas porções rasas de comida extrapola a instância da necessidade para conferir sentidos à bebida e à comida que se relacionam a sentimentos sociais externalizados e partilhados naquele momento: a água, por exemplo, sob aquelas

${ }^{4}$ Fala da personagem entre 01:48:05 e 01:48:17. 


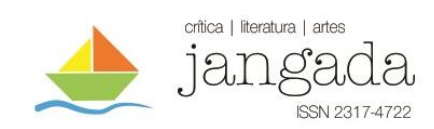

circunstâncias, adquire valor cultural de um produto sofisticado porque as condições socioculturais e históricas daquele momento permitem que assim seja feito e corroboram tal assertiva. Interessante observar que o ritual de servir-se à mesa, mesmo em meio à escassez prevalece, com a distribuição espacial de pratos e talheres, o que revela os efeitos de uma tradição cultural que atravessa os personagens.

Tem-se, posteriormente, o fato de que o problema do abastecimento alimentar começa a se articular a uma (falta de) distribuição de alimentos entre os indivíduos. Tal distribuição é reservada à escolha de um número reduzido de sujeitos que se apresentam como privilegiados por circunstâncias específicas. Dessa forma, quando estão no manicômio, o grupo de cegos em que a narrativa está centrada se vê diante de uma situação drástica: a falta de alimentos para comer. Uma das alas - a terceira - passa a dominar o fornecimento da comida alegando possuir dois trunfos: um cego natural e uma arma. Com isso, barganham a troca de alimentos pelos bens que as outras alas podem oferecer como moeda de troca. Chamados de cegos malvados, as personagens detentoras do poder e do subsídio alimentício solicitaram primeiramente objetos de valor dos cegos das outras alas sendo que, a cada pedido, a solicitação por bens aumentava enquanto a oferta de alimentos em retribuição diminuía. A crise se agrava com a última exigência do grupo dos cegos malvados:

Passada uma semana, os cegos malvados mandaram recado de que queriam mulheres. Esta inesperada, ainda que não de todo insólita, exigência causou indignação que é fácil imaginar, os aturdidos emissários que vieram com a ordem voltaram logo lá comunicar que as camaratas, as três da direita e as duas da esquerda, sem exceção dos cegos e cegas que dormiam no chão, haviam decidido, por unanimidade, não acatar a degradante imposição, objectando que não se podia rebaixar a esse ponto a dignidade humana, neste caso feminina, e que se na terceira camarata lado esquerdo não havia mulheres, a responsabilidade, se a havia, não lhes poderia ser assacada. A resposta foi curta e seca, Se não nos trouxerem mulheres, não comem. [...] (SARAMAGO, 2008, p. 165)

Neste fragmento, percebemos a utilização do poder por aqueles que possuem o suprimento básico, necessário à sobrevivência da multidão, em benefício próprio. Mais que negociar bens e alimentação, os cegos detentores da comida estavam buscando saciar seus prazeres libidinosos em troca da subsistência dos demais. Interessante perceber que, assim 
como nas duas produções artísticas do Ensaio sobre a Cegueira, também em Claude LéviStrauss (1976), ao final do livro Estruturas elementares do parentesco, a troca de mulheres ${ }^{5}$ é considerada uma moeda linguística, como se fosse uma espécie de troca de palavras ocorrendo no âmbito de um conjunto de relações linguísticas.

Para Lévi-Strauss (1976), o sujeito falante passa a existir a partir da relação com a dualidade entre os sexos e a cultura, definida pela troca das mulheres. Assim, a possibilidade de comunicação passou a ser fundada nesta troca que marcava a diferença entre homens e mulheres na sociedade, o que fornecia ferramentas para perceber a instituição do patriarcado a partir da hierarquização dos gêneros funcionando no estabelecimento da ordem simbólica que se perpetua até os dias atuais (SILVEIRA, 2016, p. 55).

$\mathrm{Na}$ análise das instituições matrimoniais, Lévi-Strauss se baseou no argumento lógico da proibição do incesto como motor fundamental da vida em sociedade. É a proibição do incesto que funda a obrigação da troca das mulheres expressando "[...] a passagem do fato natural da consanguinidade para o fato cultural da aliança" (Lévi-Strauss, 1976, p. 35).

O valor de troca não é aquele dos bens trocados. A troca tem um valor social em si mesma. Ela provê os meios de manter os homens unidos e de superimpor aos vínculos naturais do parentesco os vínculos doravante artificiais - no sentido de que são removidos dos encontros casuais ou da promiscuidade da vida familiar - da aliança governada pela regra (LÉVI-STRAUSS, 1976, p. 480).

Vale mencionarmos então, neste contexto, a afirmação de Judith Butler que, ao ler Lévi-Strauss, critica a reprodução de uma naturalidade da heterossexualidade na qual "o surgimento do pensamento do simbólico deve ter exigido que as mulheres, como as palavras, fossem coisas a ser trocadas" (BUTLER, 2003, P. 71). Desse modo, o sistema de alianças

\footnotetext{
${ }^{5} \mathrm{O}$ que se pretende, ao utilizar Lévi-Strauss, é perceber que há uma relação de troca que se apresenta entre os homens. Contextualmente vale destacar que a obra Estruturas elementares de parentesco foi criticada por feministas que percebem nos estudos de Strauss as consequências de tornar determinadas concepções de parentesco atemporais. Em Butler (2003), por exemplo, a estrutura universal de troca de mulheres baseada na lei de interdição do incesto reforça-se em laços sexuais reprodutivos específicos e proíbe outras fórmulas de vínculos sexuais como a homossexualidade feminina ou masculina, por exemplo, ao usar uma estrutura lógica totalizante. Haveria, portanto, nos escritos de Lévi-Strauss, um efeito de naturalidade da heterossexualidade.
} 


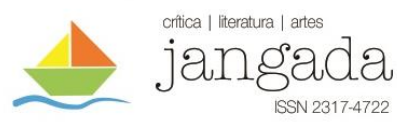

condiciona a uma reciprocidade entre homens, mas não entre homens e mulheres e desconsidera uma relação entre mulheres. Totalização e universalização semelhantes às de Strauss podem ser percebidas nas obras ficcionais nas quais as trocas e as negociações se estabelecem, majoritariamente, entre os homens. Não se tem a preocupação com a manutenção da vida de toda a comunidade senão com a satisfação social daqueles que possuem o poder de barganha nas mãos. A partir desse cenário, a escassez de alimentos para a sobrevivência de todos faz com que as comunidades entrem em discussão a fim de decidir se as mulheres devem ceder à solicitação feita ou não.

Neste momento da narrativa é proposto um sistema de troca que reflete e questiona a moralidade imposta dentro da sociedade vigente. Como moeda de troca, as mulheres se submeteriam ao papel de mantenedoras dos grupos, pagando com seu corpo. Sem qualquer juízo de valor ao que está sendo proposto na narrativa, observamos a força no questionamento que se propõe dentro da história quanto à quebra dos laços sociais ao se solicitar às mulheres casadas ou com parceiro fixo terem relações sexuais com outros homens em troca de alimentos para todos. Mesmo as personagens solteiras consideradas solteiras estão postas sob avaliação moral frente a todos neste momento. Existe um rebaixamento da figura feminina neste momento da narrativa quando ela se torna moeda de troca para a obtenção de alimentos.

Segundo Lévi-Strauss (1977), a lei da reciprocidade está pautada na troca de objetos que resulte na compensação de ambas as partes envolvidas produzindo, assim, satisfação recíproca. Isso permite, para ele, que sejam reconhecidas a validade e a universalidade das relações de reciprocidade no decorrer da história. Para ele, a reciprocidade original está associada ao casamento exogâmico que é visto como possibilidade de estabelecimento de relações de troca. Dessa forma, para o antropólogo francês a reciprocidade é uma estrutura elementar que está submetida a uma estrutura generalizada de troca, inclusive simbólica (SABOURIN, 2011).

No romance de Saramago, a proposta é feita aos cegos sem comida por aqueles que a possuem como bem, pedindo em troca as mulheres, consideradas bens valiosos, como forma de uma troca, considerada justa por aqueles que a sugerem e apresentada como forma de satisfazer ambas as partes. Alimentação, então, não é a única necessidade dos que detêm a comida e os critérios para a distribuição de alimentos. A satisfação sexual passa a ser vista como um reforço do privilégio dos que decidem quem se alimenta e quem não deve se alimentar.

Dessa forma, a interdição dos alimentos é discursiva e remete também ao terreno das práticas em que alguns são proibidos e outros são os que decidem. Tem-se uma lacuna no 
âmbito moral que negligencia princípios éticos para coisificar mulheres como moeda de troca aproximando as relações humanas de um viés utilitarista - na lógica dos cegos malvados, mulheres servem para satisfazer, assim como os alimentos saciam a fome. Reserva-se, assim, a anulação ao direito de autonomia e racionalidade dos que não pertencem ao grupo que detém os alimentos. Aos interditados, resta a negação ao direito de escolha e o afastamento de dimensões emancipatórias no que diz respeito a escolhas relacionadas ao ato de alimentar-se. Neste sentido, se configura a dinâmica de relações de poder que se manifestam no âmbito de práticas individuais e coletivas interagindo com dimensões subjetivas dos indivíduos que resultam em formas de sujeição.

Quando o pedido é feito pelos cegos malvados, o princípio de dignidade e a luta pela sobrevivência entram em conflito entre as personagens femininas e masculinas na trama:

Os homens procuraram justificar-se, que não era bem assim, que não dramatizassem, que diabo, falando é que a gente se entende, foi só porque o costume manda pedir voluntários em situações difíceis e perigosas, como esta sem dúvida o é, Estamos todos em risco de morrer à fome, vocês e nós. [...] E o que é que vocês fariam se eles, em vez de pedirem mulheres, tivessem pedido homens, o que é que fariam, contem lá para a gente ouvir. [...] agora queriam ver até onde ia a tão apregoada coerência masculina, Aqui não há maricas, atreveu-se um homem a protestar, Nem putas, retorquiu a mulher que fizera a pergunta provocadora, e ainda que as haja, pode ser que não estejas dispostas a sê-lo aqui por vocês. [...] (SARAMAGO, 2008, p. 166)

Neste trecho, a discussão entre as personagens masculinas e as femininas mostra o senso de moralidade no ato a ser praticado pelas mulheres do grupo para sustentá-los. Se for levada em consideração a afirmação feita pela mulher provocadora, todos deveriam se submeter ao papel que foi atribuído às mulheres de ter relações sexuais com os donos da comida para assim poderem comer e sobreviver naquele momento. Entretanto, o que se percebe é uma indignação quanto ao orgulho masculino e a total dependência dessa figura em relação à figura feminina para poder sobreviver em situações drásticas que afrontam a moral social, moral esta atravessada por questões discursivas que remetem a lugares social e historicamente (de) marcados. 


\section{jangada}

Situado no universo social, a partir de lugares determinados coletivamente em relação aos outros sujeitos, ocorre que quando este sujeito enuncia algo, em seu dizer aparecem "resquícios" deste lugar de onde ele fala. Por isso dizemos que o exterior à língua é um elemento caro para os estudos discursivos. Como se viu antes, o discurso não se confunde com o enunciado (enquanto fala/texto), mas é exterior à língua carecendo da língua para se materializar. Não se trata, portanto, conforme Foucault (2008), da tradução verbal de uma síntese realizada em outro lugar, mas aponta para um lugar em que se deve buscar um campo de regularidade, para diversas posições de subjetividade (SILVEIRA, 2014, p. 44-44).

As mulheres e os homens em questão não produzem enunciados a partir de uma intencionalidade fundante. $\mathrm{O}$ que se percebe é a relação de poder que atravessa o enunciado e as relações sociais e culturais que visam determinar culturalmente os papéis de gênero na sociedade. Logo, o que está em questão não é apenas um evento determinado pelos cegos malvados. É a manutenção da hierarquia patriarcal que submete mulheres aos desejos dos homens para satisfazer suas vontades. Por isso, quando mencionamos anteriormente que se trata de uma questão discursiva é sob estes termos que estamos considerando: não apenas em termos linguísticos, mas considerando discursos em meio a um terreno de práticas e representações sociais.

Na narrativa fílmica, a discussão mostrada ao espectador se passa dentro da ala em que estão o médico e sua mulher e quem profere um discurso mais racional é o oftalmologista, orientando todas as mulheres ali presentes, tendo como exemplo a sua esposa, a decidirem fazer o que julgarem ser correto para elas e não só para o grupo. Após a resposta afirmativa de concessão à condição dos cegos malvados oriunda de outra personagem, a mulher do médico diz que também irá e, assim, desencadeia outras respostas a favor da solicitação feita pelos cegos da terceira ala.

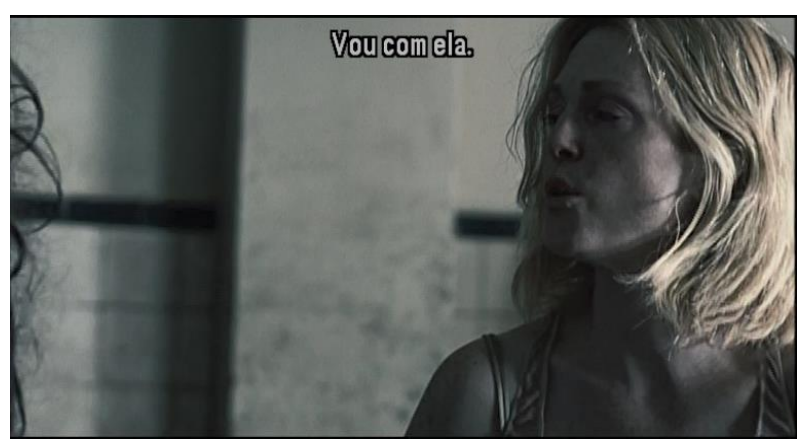

Figura 4: Cena em que a mulher do médico decide ir junto com a $1^{\mathrm{a}}$ mulher

Fonte: Meirelles, 2008 [01:10:05] 
Continuando a narrativa, o modo como as mulheres são inspecionadas pelos cegos da ala três reforça a ideia de rebaixamento da figura feminina como moeda de troca mercantil dentro das narrativas. No romance português, a descrição das personagens fica por conta do rei da ala no seguinte excerto:

Os cegos rodearam-nas, tentavam apalpá-las, mas recuaram logo, aos tropeções, quando o chefe, o que tinha a pistola, gritou, O primeiro a escolher sou eu, já sabem. Os olhos de todos aqueles homens buscavam ansiosamente as mulheres, alguns estendiam as mãos ávidas, [...] No meio da coxia, entre as camas, as mulheres eram como os soldados em parada à espera de que lhes venham passar revista. O chefe dos cegos, de pistola na mão, aproximou-se, tão ágil e despachado como se com os olhos que tinha pudesse ver. Pôs a mão livre na cega das insónias, que era a primeira, apalpou-a por diante e por detrás, as nádegas, as mamas, o entrepernas. A cega começou aos gritos e ele empurrou-a, Não vales nada, puta. Passou à seguinte, que era aquela que não se sabe quem seja, agora apalpava com as duas mãos, tinha metido a pistola no bolso das calças, Olhem que esta não é nada má, e logo se foi à mulher do primeiro cego, depois à empregada do consultório, depois à criada do hotel, exclamou, Rapazes, estas gajas são mesmo boas. [..] Apalpou a rapariga dos óculos escuros e deu um assobio, Olá, saiu-nos a sorte grande, deste gado ainda cá não tinha aparecido. Excitado, enquanto continuava a apalpar a rapariga, passou à mulher do médico, assobiou outra vez, Esta é das maduras, mas tem jeito de ser também uma rica fêmea. Puxou para si as duas mulheres, quase se babava quando disse, Fico com estas, depois de as despachar passoas a vocês. Arrastou-as para o fundo da camarata, onde se amontoavam as caixas de comida, os pacotes, as latas, uma despensa que poderia abastecer um regimento. [...] (SARAMAGO, 2008, pp. 175-176)

Neste longo fragmento acima, notamos a relação do corpo feminino como elemento crucial para que existisse o recebimento dos alimentos. Quanto mais conservadas fisicamente fossem as mulheres recebidas por aqueles cegos, maior seria a quantidade de comida recebida pelos membros daquele grupo. A reciprocidade entre mulheres e comidas de acordo com o estado das primeiras estaria diretamente associada, portanto, à quantidade de comida a ser repassada. 
Podemos perceber, então, que os critérios perpassam práticas de subjetivação e objetivação relacionadas às formas de cuidar do corpo, assinaladas pela valoração positiva que a sociedade reforça por meio das ações dos indivíduos. Dessa forma, considera-se a beleza enquanto "[...] sinônimo do gerenciamento dos corpos, no sentido de que as discursivizações sobre os padrões estéticos implicam a necessidade de padronizar os corpos a partir de um imaginário construído no universo das instâncias sociais” (SILVEIRA \& SILVA, 2014, p. 131). Tal efeito de padronização remete à existência de saberes que advém de um poder disciplinar que incide sobre corpos e sujeitos de modo a engendrar e reproduzir comportamentos relacionados à corpolatria (COURTINE, 1995). Nega-se, dessa forma, a legitimidade de outras corporeidades através da deslegitimação e exclusão dos corpos em desordem (SILVEIRA, 2012; SILVEIRA \& SILVA, 2014; SILVEIRA, 2015; SILVEIRA, AGUIAR \& COSTA, 2017).

A construção imagética no final do trecho, em que as duas mulheres são levadas para a parte traseira do recinto, onde se encontram empilhadas as comidas, reflete claramente a relação entre mulheres como objeto de troca para a comida. Como se pudessem ser amontoadas como peças, as personagens são levadas para terem relações sexuais com o chefe do bando no mesmo lugar em que se encontram os alimentos estocados. A aproximação física entre mulheres e comida no mesmo recinto reforça a produção metafórica de que mulheres seriam como comidas no sentido de existir para saciar as vontades dos homens. Além disso, a comparação feita pelo cego com a pistola, afirmando que não tinham recebido "gado" como aquele anteriormente, reforça a ideia de mercadoria presente na narrativa quanto ao corpo feminino reforçando a (re)produção da hierarquia entre os gêneros.

Na produção cinematográfica, esta cena é elaborada com o reconhecimento da voz da mulher do médico pelo chefe dos cegos, sem enfatizar a relação presente no romance entre o corpo feminino e os alimentos estocados no fundo da camarata. A revista, entretanto, é mantida no filme assim como é projetada no texto original. O destaque fica por conta do apelido dado à cega das insônias: peixe morto. No final da cena, quando as mulheres retornam à sua camarata, esta cega está morta e a sua relação com o infeliz apelido ganha destaque na narrativa: 

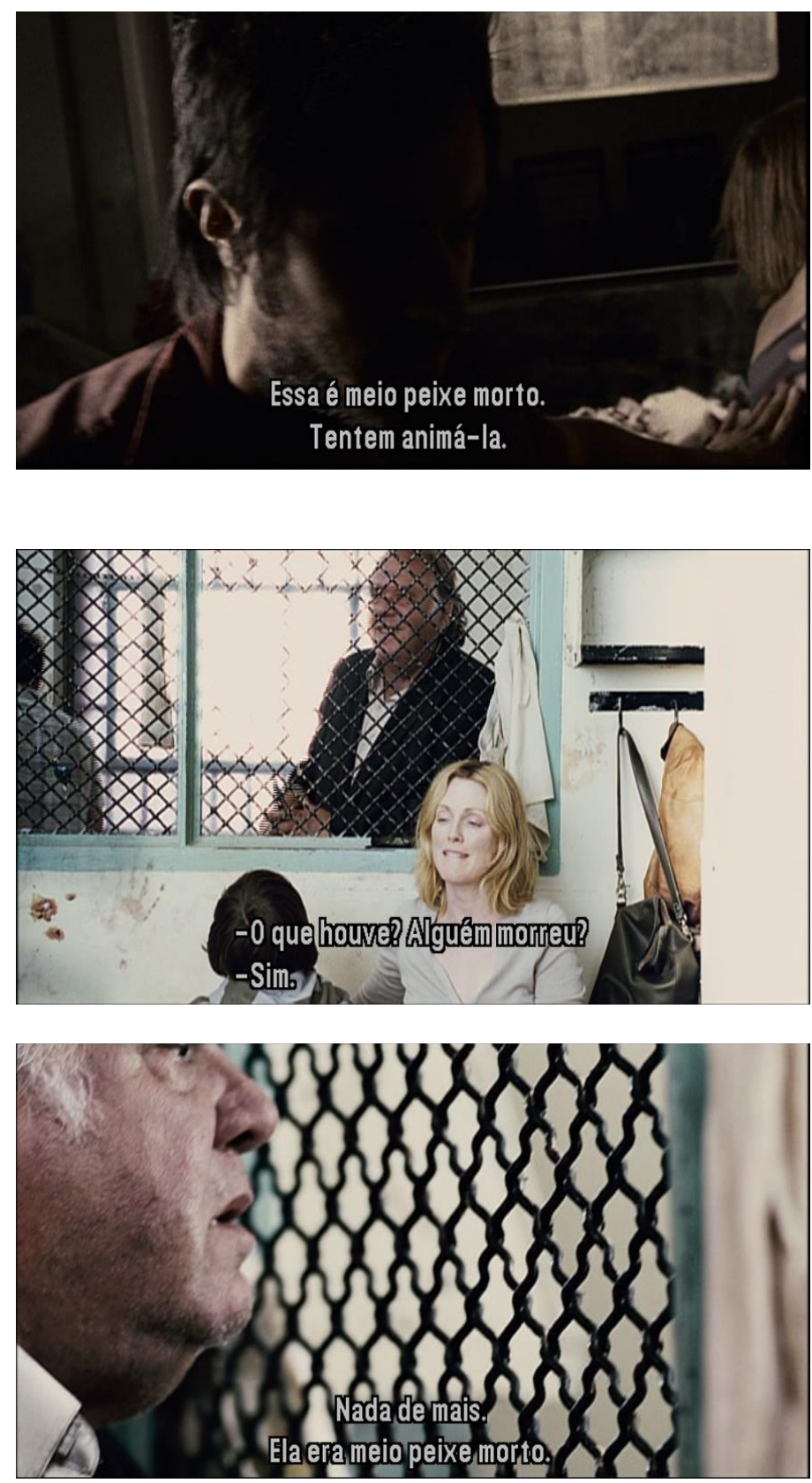

Figura 5: Cena da cega das insônias

Fonte: Meirelles, 2008 [01:14:06]

Figura 6: cego malvado perguntando sobre a morte da cega

Fonte: Meirelles, 2008 [01:19:45]

Figura 7: reação do cego malvado ao saber da morte

Fonte: Meirelles, 2008 [01:19:53]

Notamos que em ambas as narrativas, mesmo que em diferentes momentos, foi feita a relação entre o corpo feminino e algum tipo de alimento e/ou objeto de troca para sobrevivência. Assim, se de um lado, temos a comparação dos corpos com gado, do outro temos a relação do corpo de uma delas com um peixe morto. Vale ressaltar que a degradação do corpo feminino em ambos os casos e a naturalização da violência, sobretudo no que diz respeito tanto à ação empreendida quanto à associação entre "coletivo de mulheres" e "gado" e entre "mulher que não se mexe, fria, que não reage" a um "peixe morto" permite-nos corroborar nossa articulação 
a uma concepção de discurso- apoiada em Foucault (2008) - enquanto "prática que constrói os objetos a que se refere" (SILVEIRA, 2018, p. 01). Outrossim, voltar-se para a forma como as mulheres enquanto objeto de discurso foram representadas tanto na obra romanesca quanto na obra cinematográfica remete, portanto, à constatação de que todo enunciado é produzido sob determinadas condições de produção discursiva.

Por fim, analisamos a cena em que a mulher do médico encontra comida no depósito de um supermercado. Neste momento, assim como na cena anterior, a procura por comida é essencial para a sobrevivência do grupo de cegos que acompanham o médico e sua mulher. $\mathrm{O}$ comportamento social está então associado à existência ou não de alimentos para que se possa sobreviver diante daquela situação apocalíptica. Vale destacar que o trecho a seguir se passa após a saída do grupo do manicômio e da confrontação da mulher do médico com o chefe dos cegos malvados:

[...] em pouco tempo os sacos ficaram cheios, o primeiro teve de ser despejado porque não continha nada que prestasse, os outros levavam já riqueza suficiente para comprar a cidade, nem há que estranhar a diferença dos valores, basta que nos lembremos de que houve um dia um rei que quis trocar o seu reino por um cavalo, que não daria ele se estivesse a morrer de fome e lhe acenassem com estes sacos de plástico. [...] Antes, porém, a mulher do médico senta-se no chão, abre uma embalagem de chouriço, uma outra de fatias de pão negro, uma garrafa de água, e, sem remorso, come. [...] (SARAMAGO, 2008, pp. 223-224)

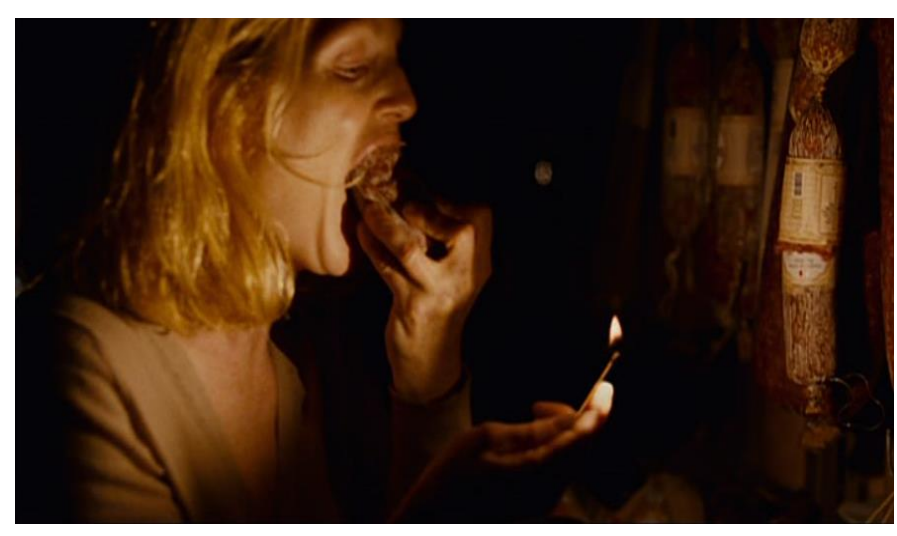

Figura 8: Mulher comendo

Fonte: Meirelles, 2008 [01:34:29] 


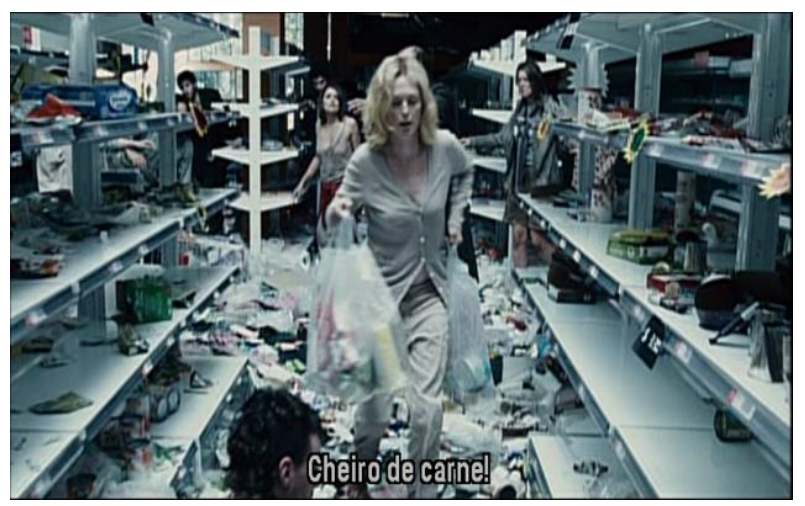

Figura 9: Mulher saindo do mercado

Fonte: Meirelles, 2008 [01:35:05]

Neste trecho, a valorização da comida como moeda de troca por sua escassez se torna evidente, levando-se em consideração a relação que a própria narrativa faz com outra história do rei que oferece seu reino por um cavalo. Conseguir enxergar em um mundo caótico repleto de pessoas cegas é um privilégio e uma maldição. Maldição porque ela percebe sem a privação do sentido da visão o que ocorre à sua volta. Privilégio porque consegue encontrar os alimentos que estiverem ao seu alcance. O cuidado de si e dos outros aqui se torna preponderante, visto que ela não utiliza de sua visão para beneficiar-se frente aos demais, explorando-os. Por outro lado, os que lhe são desconhecidos se tornam estranhos ao seu auxílio. Dessa forma, a fala da última cena (Cheiro de carne!) soa tanto como reflexo de uma necessidade quanto uma possível ameaça de alguém que pode querer lhe arrancar os alimentos que conseguiu.

Neste momento, a mulher do médico possui uma riqueza inestimável em suas mãos e, se fosse o chefe dos cegos, utilizaria tais bens em troca de poder e status. Entretanto, tal índole não lhe é atribuída, pois ela não se identifica com tal comportamento, ainda mais porque, desde o início, ela já possuía uma vantagem sobre os demais, que a era a de poder ver. Na produção cinematográfica, notamos o destaque dado à personagem enquanto come um pedaço de chouriço e sua luta para sair do supermercado sem que os outros cegos ali presentes lhe roubassem a comida encontrada. Neste instante, ela tem consigo o saber (tem conhecimento e visão para encontrar alimentos) e o sabor.

\section{CONSIDERAÇÕES FINAIS}

O presente artigo visou apresentar pronunciamentos enunciativos de compreensão de excertos extraídos do romance Ensaio sobre a cegueira, de José Saramago e do filme homônimo, dirigido pelo brasileiro Fernando Meirelles. Consideramos que a comida é também fonte de 
expressão e não apenas uma necessidade articulando-nos, portanto, ao bojo de pesquisas que vem sendo desenvolvidas desde a década de 1930 no campo das Ciências Humanas.

Por acreditar que a alimentação não é apenas uma necessidade física, concluímos que a necessidade de nos alimentarmos está também associada à expressão de hábitos, rituais e compartilhamento de significados social e culturalmente partilhados. Também a forma como os seres humanos se comportam na ausência de alimentos ou perante a interdição de alimentos diz muito sobre formas de subjetivação atravessadas por relações de poder que incidem sobre os corpos. Nas obras ficcionais mencionadas, a interdição dos alimentos é discursiva e remete também ao terreno das práticas em que alguns são proibidos e outros são os que decidem, negligenciando-se princípios éticos para coisificar mulheres como moeda de troca aproximando as relações humanas de um viés utilitarista. Aos interditados, resta a negação ao direito de escolha e o afastamento de dimensões emancipatórias no que diz respeito a escolhas relacionadas ao ato de alimentar-se. Concluímos, neste contexto, que as relações de poder atravessam práticas individuais e coletivas interagindo com dimensões subjetivas dos indivíduos que resultam em formas de sujeição.

A questão do saber e do sabor, preconizadas por Roland Barthes no contexto em questão permite que associemos a interdição do sabor aos critérios pré-estabelecidos de distribuição de alimentos bem como à escassez de alimentos, elementos que se fazem presentes tanto na obra literária quanto cinematográfica. A necessidade de alimentação instaura hábitos, comportamentos e modos de agir atravessados por relações de poder na obra de José Saramago e de Fernando Meirelles. Dessa forma, o gosto pela Literatura e pelo Cinema se dá, paradoxalmente, em meio a um enredo de interdição de alimentos. Em Barthes, todo saber tem equivalência a um certo sabor. Se o ato de comer gira em torno do instinto da fome e da satisfação, Saramago e Meirelles fazem bem mais que nos satisfazer ao nos servir com suas obras: o que fazem é ampliar os sentidos para ver o mundo à nossa volta e apresentam uma iguaria repleta de nuances, temperos e molhos que só a palavra bem elaborada pode nos proporcionar.

\section{REFERÊNCIAS BIBLIOGRÁFICAS}

BARTHES, Roland. O prazer do texto. Lisboa: Edições 70, 1988. 
BRAUDEL, Fernand. Civilização material, economia e capitalismo: séculos XV-XVIII. Tradução de Telma Costa. São Paulo: Martins Fontes, 1995.

BUTLER, Judith. O parentesco é sempre tido como heterossexual? Cadernos Pagu. Campinas, n. 21, p. 219-260, 2003.

CARNEIRO, Henrique. Comida e sociedade: uma história da alimentação. Rio de Janeiro: Campus, 2003.

COURTINE, Jean Jaques. Os stakhanovistas do narcisismo. In: SANT'ANNA, Denise Bernuzzi de. (org.) Políticas do corpo: elementos para uma história das práticas corporais. São Paulo: Estação Liberdade, 1995.

ENSAIO sobre a cegueira (Blindness). Direção de Fernando Meirelles. São Paulo: O2 Filmes, 2008. DVD, 121 min., color.

FLANDRIN, Jean-Louis; MONTANARI, Massimo. História da Alimentação. Tradução de Luciano Vieira Machado, Guilherme J. F. Teixeira. São Paulo: Estação Liberdade, 1998.

FOUCAULT, Michel. A arqueologia do saber. Tradução de Luiz Felipe Baeta Neves. Rio de Janeiro: Forense Universitária, 2008.

. Microfísica do poder. Organização e tradução de Roberto Machado. Rio de

Janeiro: Edições Graal, 1979.

HENRIQUES, Isabela. Mascarpone: o que é e como fazer em casa. PORTAL TERRA, 13 de março de 2018. Disponível em: https://www.terra.com.br/vida-eestilo/culinaria/tudogostoso/mascarpone-o-que-e-e-como-fazer-emcasa,244e3a2f0e7bed5355729dafa5c4a899c0vbthcv.html Acessado em 03 de junho de 2018. HUTCHEON, Linda. Uma teoria da adaptação. Tradução de André Cechinel. Florianópolis: Editora da UFSC, 2011.

LE GOFF, Jacques; NORA, Pierre. (orgs.). Faire de l'histoire: nouveaux problèmes. Paris: Gallimard, 1974.

. Faire de l'histoire: nouvelles approaches. Paris: Gallimard, 1974.

Faire de l'histoire: nouveaux objets. Paris: Gallimard, 1974.

. História, novos problemas. Tradução de Henrique Mesquita. Rio de Janeiro:

Francisco Alves, 1976.

História, novas abordagens. Tradução de Henrique Mesquita. Rio de Janeiro: Francisco Alves, 1976.

História, novos objetos. Tradução de Henrique Mesquita. Rio de Janeiro: Francisco Alves, 1976.

LEVI-STRAUSS, Claude. As estruturas elementares do parentesco. São Paulo: Vozes, 1976. Introduction à l'œuvre de Marcel Mauss. In: MAUSS, M. Sociologie et Anthropologie. 7. ed. Paris: PUF, 1977.

MEDEIROS, Symonne de Albuquerque. Introdução à Gastronomia. Recife: Secretaria de Educação e Esportes do Estado de Pernambuco, 2014.

PITTE, Jean-Robert. Gastronomie Française: histoire et geographie d'une passion. Paris: Fayard, 1991.

Gastronomia Francesa: História e Geografia de Uma Paixão. Porto Alegre: L\&PM, 1993. 


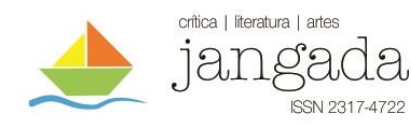

SABOURIN, Eric. Teoria da Reciprocidade e sócio-antropologia do desenvolvimento. Sociologias. Porto Alegre, v. 13, n. 27, p. 24-51, mai./ago. 2011.

SANTOS, Carlos Roberto Antunes dos. A alimentação e seu lugar na história: os tempos da memória gustativa. História: Questões \& Debates. Curitiba, n. 42, p. 11-31, 2005.

SARAMAGO, José. Ensaio sobre a cegueira. 44. Reimpressão. São Paulo: Companhia das Letras, 2008 [1995].

SILVEIRA, Éderson Luís. A dissolução da identidade em corpos complexos: Para além do binarismo masculino/feminino. Temporalidades. Belo Horizonte, v. 7, p. 148-175, 2015.

. Corpos silenciados em busca de identidade: Espelhos que refletem a falta. PRACS:

Revista Eletrônica de Humanidades do Curso de Ciências Sociais da UNIFAP. Macapá, v. 5, p. 29-40, 2012.

. Édipo (não é) rei: Foucault, Butler e o sexo em discurso. 2016. 116 p. Dissertação (Mestrado) - Universidade Federal de Santa Catarina, Centro de Comunicação e Expressão, Programa de Pós-Graduação em Linguística, Florianópolis, 2016.

Pensar com Foucault: história, sujeito e discurso. Cadernos discursivos. Catalão, v. 1 n. 1, p. 38 - 50, 2014.

. SILVEIRA, Éderson Luís; SILVA, Francisco Vieira da. O corpo em (des)ordem: entre a falta e o absurdo. Entrelinhas. São Leopoldo, v. 8, p. 131-144, 2014.

SILVEIRA, Éderson Luís; AGUIAR, Gean Pablo Silva; COSTA, Leonard Christy Souza. Alimentos (in) disciplinados: a beleza que (não) se põe na mesa. Caminhos em linguística aplicada. Taubaté, v. 17, p. 484-508, 2017.

SILVEIRA, Éderson Luís. Você não está sozinha: vulnerabilidade, ações protetivas e (tentativas de) interdição do abuso sexual nos transportes públicos. Interletras. Dourados, v. 07, p. 1597-1807, 2018.

SPANG, Rebecca L. A invenção do restaurante: Paris e a moderna cultura gastronômica. Tradução de Cynthia Cortes e Paulo Soares. Rio de Janeiro: Record, 2003.

The Invention of the Restaurant: Paris and Modern Gastronomic Culture. Cambridge: Harvard University Press, 2000.

SEIXO, Maria Alzira. Os sabores da literatura ou como a gastronomia se apoia nos modos de dizer. ABRIL - Revista do Núcleo de Estudos de Literatura Portuguesa e Africana da UFF. Niterói, v. 6, n. 12, abril de 2014. 